\title{
Surgery for Unruptured Intracranial Aneurysms in the ISAT and ISUIA Era
}

\author{
Laurent Thines, Philippe Bourgeois, Jean-Paul Lejeune
}

\begin{abstract}
Background: The ISAT and ISUIA studies, along with the improvement of endovascular treatment (EVT) have strongly influenced the management of intracranial aneurysms (IAs). We present our experience in the microsurgical treatment of unruptured IAs (UIAs) in this context. Methods: We retrospectively reviewed a consecutive series of non-giant UIAs selected for surgery during a fiveyear period. Patients and aneurysms characteristics, surgical results and outcome assessed by the Glascow Outcome Scale (GOS) at three month follow-up were studied. Results: Eighty-five patients underwent 93 surgical procedures to obliterate 113 UIAs. Those were incidental in $89 \%$ of the cases and mainly located on the middle cerebral artery (65\%). Patients were assigned to surgery according to their medical history (young, previous subarachnoid haemorrhage), aneurysm characteristics (wide neck, branch at the neck, "small" size, associated "surgical" aneurysm) or failure of EVT (5\%). Operatively, $48 \%$ of UIAs had thin wall or blebs and $71 \%$ were occluded with one titanium clip. Thrombectomy or temporary clipping were necessary in $4 \%$ and $11 \%$ of the cases, three aneurysms peroperatively ruptured, four were deemed unclippable, three paraclinoid UIAs had an intracavernous residue and $16 \%$ were wrapped because of a small neck remnant (class 2). The mortality rate was $0 \%$ and $4 \%$ of the patients experienced a definitive major neurological deterioration. Final GOS was unchanged in $96 \%$ of the patients. Conclusions: Despite reduction in operative cases and in appropriately selected patients ineligible to EVT, microsurgical clipping of non-giant anterior circulation UIAs can still achieve good outcome with very low mortality and neurological morbidity.
\end{abstract}

RÉSUMÉ: La chirurgie des anévrismes intracrâniens non rompus à l'ère d'ISAT et d'ISUIA. Contexte : Les études ISAT et ISUIA ainsi que l'amélioration du traitement endovasculaire (TEV) ont fortement influencé le traitement des anévrismes intracrâniens (AI). Nous présentons notre expérience du traitement microchirurgical des AI non rompus (AINR) dans ce contexte. Méthode : Nous avons revu rétrospectivement une série consécutive d'AINR non géants pris en charge chirurgicalement sur une période de 5 ans. Les caractéristiques des patients et des anévrismes, les résultats chirurgicaux et l'évolution clinique évaluée au moyen de l'échelle de Glasgow à trois mois ont été examinés. Résultats : Quatre-vingt-cinq patients ont subi 93 interventions chirurgicales pour exclure 113 AINR. Ces anévrismes avaient été découverts fortuitement chez $89 \%$ des patients et étaient localisés préférentiellement au niveau de l'artère cérébrale moyenne (65\%). Les patients étaient orientés vers la chirurgie selon leur histoire médicale (patient jeune, antécédent d'hémorragie sous-arachnoïdienne), les caractéristiques de l'anévrisme (collet large, branche artérielle au collet, petite taille, autre anévrisme « chirurgical » associé) ou échec du TEV (5\%). Au moment de la chirurgie, on a constaté que 48\% des AINR avaient une paroi mince ou des phlyctènes en surface et $71 \%$ ont été exclus au moyen d'un seul clip en titane. Nous avons dû faire une thrombectomie et réaliser un clippage temporaire respectivement chez $4 \%$ et $11 \%$ des patients. Trois anévrismes se sont rompus pendant la chirurgie. Quatre anévrismes ont été considérés comme nonclippable ; 3 AINR paraclinoïdiens gardaient une portion intracaverneuse résiduelle et nous avons dû procéder à l'enrobage d'un petit collet résiduel (classe 2) chez $16 \%$ des patients. Le taux de mortalité a été de $0 \%$. Quatre pour cent des patients ont présenté une détérioration neurologique permanente majeure. Le score final selon l'échelle de Glasgow était inchangé chez 96\% des patients. Conclusions : Malgré une diminution du nombre de cas traités chirurgicalement et chez des patients bien sélectionnés qui ne sont pas éligibles au TEV, le clipping microchirurgical des AINR non géants de la circulation antérieure peut offrir de bons résultats fonctionnels et comporte un très faible taux de mortalité et de morbidité neurologique.

Can J Neurol Sci. 2012; 39: 174-179

Recent multicenter studies have raised the question whether endovascular treatment (EVT) could have a lower morbimortality or not than microsurgical treatment (MST) for the management of ruptured ${ }^{1}$ and unruptured intracranial aneurysms (UIAs). ${ }^{2,3}$ It has also been suggested that very small and anterior circulation UIAs would have a very low risk of spontaneous rupture, raising questions about the necessity of even treating some of them. ${ }^{2}$ Those results completely remodelled the landscape of cerebrovascular surgery everyday practice all over the world. In France, they strongly influenced the therapeutic management of intracranial aneurysms and dramatically reduced the volume of surgically treated patients, to a point that, in some centres, the preservation of surgical expertise and training is endangered. ${ }^{4,5}$ With the improvement of EVT techniques, UIAs are rarely offered surgical treatment unless the angioarchitecture is very unfavourable or EVT has already failed. ${ }^{5}$ We present in this article our experience and results in the MST of UIAs in this context.

From the Department of Neurosurgery, Lille University Hospital, 59037 Lille cedex, Université Lille Nord de France, F-59000 Lille, France.

Received March 21, 2011. Final Revisions Submitted October 25, 2011. Correspondence to: Laurent Thines, Department of Neurosurgery, Lille University Hospital, rue du Pr. E. Laine, 59037 Lille Cedex, France. Email: laurent.thines@wanadoo.fr 


\section{Clinical Material and Methods}

\section{Study population}

In our institution, we currently treat approximately 250 ruptured and unruptured intracranial aneurysms per year. In recent years, EVT was the favoured treatment for $60 \%$ of aneurysms and the remaining $40 \%$ were referred to MST. Cases of patients with UIAs are discussed during weekly cerebrovascular meetings and managed by a multidisciplinary neurovascular team, with close collaboration between neurologists, interventional neuroradiologists and neurosurgeons.

Patients are prospectively recorded in the neurovascular database, from which we performed a retrospective analysis of a consecutive series of UIAs selected for surgery during a fiveyear period (January 2000 to December 2005). Patients carrying giant aneurysms $(>25 \mathrm{~mm})$ were excluded from the study.

\section{Surgical procedure}

One of the experienced neurovascular surgeons of our department conducted the surgical procedure in $87 \%$ of the cases, through a classical fronto-pterional approach (except for pericallosal or PICA aneurysms). MST was classically performed using titanium Yasargil clips (Braun Aesculap, Tuttlingen, Germany). When necessary, a temporary clipping under mild hypothermia, controlled hypertension and burst suppression was performed to secure the final clipping. If the aneurysm couldn't be completely excluded without compromising the patency of collateral arterial branches at the aneurysm base, a neck remnant was preserved and wrapped with periosteum. When the aneurismal neck was perfectly exposed and clipped, the sac was then punctured to ensure complete exclusion and a postoperative angiography was not routinely scheduled. When difficulties were encountered during the exposition or the clipping, or if the surgeon had any doubt about the quality of the treatment, a postoperative DSA was performed (16\% in this series).

\section{Studied parameters}

Patients' characteristics were recorded: age at assessment, sex, vascular risk factors (high blood pressure -HBP, smoking) and history of subarachnoid haemorrhage (SAH). Aneurysm characteristics were studied: mode of diagnosis (context, imaging technique), location, size, number, surgical aspects (thickness of the wall, presence of blebs) and reasons for referral to surgery. Surgical procedures were analysed: time to surgery, main technique (number of clips, complications), additional technique (temporary clipping, wrapping) and anatomical result according to Raymond's classification. ${ }^{6,7}$ Postoperative clinical complications were all monitored. Initial and final outcomes were assessed with the Glasgow Outcome Scale (GOS) $(1=$ dead, $2=$ vegetative state, $3=$ severe disability, $4=$ moderate disability, $5=$ good recovery) at discharge and at three month follow-up.

\section{Statistical analysis}

Statistical analysis used Chi-square tests to assess relationship between vascular risk factors and aneurysm wall aspects; age or prior history of SAH and aneurysm size in treated patients; aneurysm wall thickness and temporary clipping, number of clips applied or presence of aneurysmal remnants; and decrease in the GOS score at discharge and age, aneurysm wall thickness or location, presence of multiple aneurysms or the use of temporary clipping. When subgroups were too small $(<5)$, the Fisher exact test was applied. Statistical significance was assigned for $\mathrm{P}$ values $<0.05$.

\section{RESULTS \\ General data}

Eighty-five patients (27 Male (M), 58 Female (F), mean age 45 years) underwent definitive MST of at least one UIA during the study period. Patient and aneurysm characteristics are summarized in Table 1. Vascular risk factors, namely HBP and/or smoking were found in $56 \%$ of the cases. Ninety-three procedures were performed to obliterate 113 UIAs (46\% of the patients carrying multiple aneurysms). UIAs were in their vast majority incidental and the diagnosis was done on brain MRI, cerebral angiography and computed tomogram (CT) scan respectively in 55\%, 32\% and $13 \%$ of the cases. The location was the middle cerebral artery and the anterior circulation respectively in $65 \%$ and $86 \%$ of the aneurysms.

\section{Management decision-making process}

Patients were assigned to surgery after a multidisciplinary meeting and according to their medical history (young age, previous subarachnoid haemorrhage), aneurysm characteristics contraindicating EVT (wide neck, branch at the neck, very small size, associated "surgical" aneurysm) or failure of a previous EVT attempt. Patients were younger than 50-years-of-age in $66 \%$ of the cases or had suffered from a previous SAH in $27 \%$ of the cases. Those two parameters influenced the decision in favour of treatment respectively in $46 \%$ and $16 \%$ of the cases. Patients over 50 and patients without prior SAH had significantly larger aneurysms: respectively $>10 \mathrm{~mm}(\mathrm{P}=0.002)$ and $>7 \mathrm{~mm}(\mathrm{P}=0.002)$. The main argument for referring patients to surgery was (per aneurysm): wide neck 57\%, association with an other "surgical" aneurysm 17\%, collateral branch arising from the neck or sac $12 \%$, EVT failure 5\%, very small size 5\%, optic nerve compression $1 \%$ and others, including patient's preference, $3 \%$. Mean time to surgery was five months and during that latency period none of the aneurysms had ruptured.

\section{Operative findings}

Operatively, $48 \%$ of UIAs had a thin wall with translucent areas or blebs. On the contrary, $30 \%$ of the aneurysms had a thick or rigid wall due to atherosclerosis, calcifications or thrombosis. Atherosclerotic presentation was significantly associated with $\operatorname{HBP}(\mathrm{P}=0.03)$, smoking $(\mathrm{P}=0.01)$ or both $(\mathrm{P}=$ 0.002). In most of the cases, the procedure was relatively straightforward and the aneurysm was obliterated with the application of just one $(71 \%)$ or two (20\%) titanium clip(s). Remodelling of the aneurysm with three or more clips was necessary in $4 \%$. Additional techniques, like intra-aneurismal thrombectomy or temporary clipping, were necessary 
Table 1: Demographic, morphological and clinical characteristics of 85 unruptured intracranial aneurysms patients at first assessment

\begin{tabular}{|c|c|c|c|}
\hline Feature & Subgroup & Total & $(\%)$ \\
\hline Total number of patients & - & 85 & 100 \\
\hline \multirow[t]{5}{*}{ Demographics } & Age (mean, SD, range) yrs & $45,10,20-71$ & - \\
\hline & Female gender & 58 & 68 \\
\hline & HBP & 36 & $42 \%$ \\
\hline & Smoking & 27 & $32 \%$ \\
\hline & Smoking and HBP & 14 & $16 \%$ \\
\hline Neurological status & GOS $=5$ (per procedure) & 87 & $94 \%$ \\
\hline Total number of aneurysms & - & 113 & 100 \\
\hline \multirow[t]{8}{*}{ Aneurysms location } & Middle cerebral artery & 73 & $65 \%$ \\
\hline & PcomA & 12 & $13 \%$ \\
\hline & AChoA & 3 & $13 \%$ \\
\hline & AComA & 8 & $7 \%$ \\
\hline & $\mathrm{CO}$ & 7 & $6 \%$ \\
\hline & Carotid termination & 5 & $4 \%$ \\
\hline & Pericallosal & 4 & $4 \%$ \\
\hline & PICA & 1 & $1 \%$ \\
\hline Size & (mean, range) $\mathrm{mm}$ & $6.3,2-15$ & - \\
\hline \multirow[t]{5}{*}{ Mode of diagnosis } & Incidental & 52 & $62 \%$ \\
\hline & $\begin{array}{l}\text { Previous SAH from associated } \\
\text { aneurysm }\end{array}$ & 23 & $27 \%$ \\
\hline & Embolic events & 6 & $7 \%$ \\
\hline & Perimesencephalic haemorrhage & 2 & $2 \%$ \\
\hline & Other & 2 & $2 \%$ \\
\hline
\end{tabular}

$\mathrm{HBP}=$ high blood pressure, GOS = Glasgow Outcome Scale, PcomA = posterior communicating artery, $\mathrm{AchoA}=$ anterior choroidal artery, $\mathrm{AcomA}=$ anterior communicating artery, $\mathrm{CO}=$ carotido-ophthalmic, $\mathrm{PICA}=$ posterior and inferior cerebellar artery, $\mathrm{SAH}=$ subarachnoid haemorrhage

respectively in $4 \%$ and $11 \%$ of the cases. The use of several clips or temporary clipping was closely correlated with the aneurysm wall thickness (respectively $\mathrm{P}=0.004$ and $\mathrm{P}=0.04$ ). Three aneurysms peroperatively ruptured, four aneurysms (4\%) were deemed unclippable (one transitional carotido-cavernous, one thrombosed and calcified postero-carotid, two very small $(1 \mathrm{~mm})$ middle cerebral and postero-carotid aneurysms), three paraclinoid transitional UIAs were left with an intracavernous residue $(3 \%)$ and $18(16 \%)$ were wrapped because of a small neck remnant. Overall complete (class 1) or near complete occlusion (class $2=$ small neck remnant) was achieved in $93 \%$ of the cases. Atherosclerosis or calcifications were frequently associated with aneurismal remnants (47\%) but this did not reach statistical significance $(\mathrm{P}>0.05)$.

\section{Clinical outcome}

The postoperative course of patients after 93 microsurgical procedures is summarized in Table 2. Minor immediate postoperative complications occurred in $18 \%$ of the cases and major complications (aphasia, motor deficit or memory loss) in $9 \%$ of the cases but both led to a definitive neurological deficit in $4 \%$ of the cases. The mortality rate was $0 \%$. Initial GOS was 5 in $97 \%$ of the cases because some patients had suffered previous $\mathrm{SAH}$ or stroke. Immediate postoperative outcome was stable in $92 \%$ of the patients and decreased in seven patients (GOS 5 to 4 in five, GOS 5 to 3 in one and GOS 4 to 3 in one). Clinical worsening at initial discharge was independent of age, aneurysm wall thickness, use of temporary clipping and treatment of multiple aneurysms in the same procedure $(\mathrm{P}>$ $0.05)$ but significantly correlated $(\mathrm{P}=0.007)$ to aneurysm location on the anterior communicating artery or the posterior circulation (posterocarotid, PICA). Final GOS at three months was unchanged compared with the preoperative GOS in $96 \%$ of patients (recovery of three previously deteriorated patients). Four patients remained definitively disabled (GOS 5 to 4 in three, GOS 4 to 3 in one). Outcome was comparable between patients having single or multiple UIAs $(\mathrm{P}>0.05)$. Overall no statistical difference was found between preoperative, discharge and three month follow-up GOS scores $(\mathrm{P}>0.05)$.

\section{Discussion}

As it has been shown recently, the improvement of management strategies has reduced case-fatality rates of 
Table 2: Postoperative complications after 93 microsurgical procedures

\begin{tabular}{|c|c|c|c|c|}
\hline \multirow[t]{2}{*}{ Feature } & \multicolumn{2}{|c|}{$\begin{array}{c}\text { Immediate } \\
\text { postoperative course }\end{array}$} & \multicolumn{2}{|c|}{ Definitive deficit } \\
\hline & $\mathrm{Nb}$ & $\%$ & $\mathrm{Nb}$ & $\%$ \\
\hline \multicolumn{5}{|l|}{ Minor complications } \\
\hline Seizure & 7 & $8 \%$ & - & - \\
\hline Anosmia & 3 & $3 \%$ & 3 & $3 \%$ \\
\hline $\mathrm{III}^{\text {rd }}$ nerve palsy & 1 & $1 \%$ & 1 & $1 \%$ \\
\hline Swallowing disturbance $(\mathrm{X})$ & 1 & $1 \%$ & - & - \\
\hline Meningitis & 1 & $1 \%$ & - & - \\
\hline Non surgical CSH & 1 & $1 \%$ & - & - \\
\hline $\begin{array}{l}\text { Silent frontal ischemia or } \\
\text { contusion on CT }\end{array}$ & 2 & $2 \%$ & - & - \\
\hline $\begin{array}{c}\text { Silent remote cerebellar } \\
\text { haemorrhage on CT }\end{array}$ & 1 & $1 \%$ & - & - \\
\hline - TOTAL - & 17 & $18 \%$ & 4 & $4 \%$ \\
\hline \multicolumn{5}{|l|}{ Major complications } \\
\hline $\begin{array}{l}\text { Aphasia and/or } \\
\text { motor deficit }\end{array}$ & 6 & $6 \%$ & 2 & $2 \%$ \\
\hline Memory disturbance & 3 & $3 \%$ & 2 & $2 \%$ \\
\hline Death & 0 & $0 \%$ & 0 & $0 \%$ \\
\hline - TOTAL - & 9 & $9 \%$ & 4 & $4 \%$ \\
\hline Ref. $=93$ procedures & & & & \\
\hline
\end{tabular}

$\mathrm{X}$ : vagus nerve, $\mathrm{CT}$ : computerized tomography, $\mathrm{CSH}$ : chronic subdural hematoma

aneurismal SAH by $17 \%$ over the last three decades. ${ }^{8}$ However, aneurysm rupture remains a devastating disease and despite progress in microsurgical, endovascular and neurocritical care treatments, it is still associated with mortality rates as high as 30$45 \%$ and morbidity in survivors of $30-50 \% .^{3,9,10}$ If there are few debates about the need to treat a ruptured aneurysm regarding the poor prognosis in case of re-rupture, ${ }^{1,11,12}$ there are no uniform guidelines about treatment indications for UIAs. To solve this problem, continuing efforts have been employed in recent years to better understand the natural history of UIAs and particularly their risk of haemorrhage. Several factors have been linked to a higher risk of rupture: size, prior $\mathrm{SAH}$, posterior circulation location, HBP, smoking or family history of intracranial aneurysm or $\mathrm{SAH}^{2,3,13-21}$ In the recent literature, a certain consensus arose to support treatment for definite subgroups of UIAs, like those above $>7-10 \mathrm{~mm}$, occurring in young patients $(<50$-year-old) particularly if located on the posterior circulation or associated with an other previously ruptured aneurysm. 2,3,14,15,18,21-23 Our results showed that our decision making process conformed to those general recommendations.

When a neurovascular team is considering an UIA for treatment, it is also of paramount importance to accurately determine the individualized balance of risks and benefits of treatment versus natural history. Physicians have to take into account the outcomes provided by the literature, but more importantly, have to evaluate their own mortality / morbidity rates and the factors influencing them. In previous studies, conflicting results about MST have been presented with mortality varying from 0 to $3.8 \%$ and morbidity from 1.5 to
$12 \% .^{2,3,24,25}$ In their meta-analysis in 1994 , King et al found a mortality rate of $1 \%$ and a morbidity rate of $4.1 \% .{ }^{26} \mathrm{~A}$ few years later, Raaymakers et al estimated that the mortality and morbidity rates for non-giant unruptured aneurysms were respectively $0.8 \%$ and $1.9 \%$ for anterior circulation aneurysms, and $3.0 \%$ and $12.9 \%$ for posterior circulation aneurysms. ${ }^{24} \mathrm{We}$ showed in our study that obtaining a mortality rate of $0 \%$ was feasible, which is of paramount importance when comparing MST with EVT series that usually report a mortality rate $>1 \%$. Our major morbidity rate was below 5\% (96\% of patients with stable GOS score), which is the usual outcome achieved with MST of UIAs in appropriately selected patients by experienced neurovascular teams in high-volume centres. It is interesting to note that despite the strong reduction in operated cases in France and in our institution, we managed to maintain the quality of surgical results compared with older series, probably because of the improvement of surgical techniques and monitoring, peroperative and postoperative care.

However, we have to acknowledge that the present results are mainly relevant for anterior circulation aneurysms since few posterior circulation aneurysms were treated. Nevertheless, in this selected series of UIAs, MST seems competitive with EVT in terms of clinical outcome and also of anatomical results. For comparison, recent interventional neuradiological studies reported the following mortality and morbidity: 0 to $3.4 \%, 0.27$ to $7.7 \%{ }^{2,27-32}$ Aneurysm recurrence occurs in 20 to $30 \%$ of the cases at delayed follow-up in most of the studies, necessitating retreatment in about 3 to $10 \%$ of the cases..$^{2,27,28,31,32}$ As proposed by other authors, ${ }^{15,33,34}$ and because of the uncertainty about the 
durability of coiling, MST could be proposed as the first therapeutic option for anterior circulation UIAs (essentially middle cerebral artery, carotid termination or pericallosal aneurysms) above $7 \mathrm{~mm}$ in young patients $(<40$ years-of-age $)$ particularly if associated with prior SAH. Future results from randomized studies, such as the CURES Trial 2 conducted by our Canadian colleagues ${ }^{35}$, will be very helpful in determining which treatment modality would be more beneficial for patients carrying UIAs.

The main limitation of this study is the low level of evidence provided (case series without control) and its retrospective aspect. Furthermore, interpretation of the clinical results should be moderated because it especially applies to non-giant anterior circulation UIAs. Indeed, this series was collected in the era of the ISAT and the ISUIA studies when the consensus was to propose MST for UIAs unsuitable for coiling and mainly located on the anterior circulation. Giant aneurysms were also excluded from the study because they had a very different behaviour and postoperative prognosis. Furthermore, the accuracy of outcome results might be questionable in so far as it was only measured with the GOS score: no complimentary neurocognitive or quality of life scales were used ${ }^{36,37}$ and the clinical follow-up was not performed by an independent neurologist but by the operating surgeon. Finally, postoperative angiographies were not available for a majority of patients. However, when accessible, these exams confirmed the surgical findings, in terms of aneurysm remnants, in $79 \%$ of the cases, and underestimated remnants compared with operative inspection in $21 \%$ of the cases. This was probably due to the lack of three-dimensional reconstructions at the time of patients management.

\section{ConClusion}

The management decision-making with respect to non-giant UIAs is not always simple because of their relatively benign natural history in the short term and the relative lack of reliable evidence. If a specific treatment is required, its occlusion rate has to be high $(>90 \%)$ and its morbidity-mortality rates have to be maintained very low (close to $0 \%$ ). In appropriately selected patients, MST of UIAs can offer favourable outcome in $96 \%$ of the patients. Thus, it remains an efficient and safe therapeutic option for the management of UIAs ineligible to EVT, particularly in patients carrying individual risk factors of aneurysm rupture.

\section{REFERENCES}

1. Molyneux AJ, Kerr RS, Yu LM, et al. International subarachnoid aneurysm trial (ISAT) of neurosurgical clipping versus endovascular coiling in 2143 patients with ruptured intracranial aneurysms: a randomized comparison of effects on survival, dependency, seizures, rebleeding, subgroups, and aneurysm occlusion. Lancet. 2005;366(9488):809-17.

2. Wiebers DO, Whisnant JP, Huston J, III, et al. Unruptured intracranial aneurysms: natural history, clinical outcome, and risks of surgical and endovascular treatment. Lancet. 2003;362 (9378): 103-10

3. Investigators ISUIA. Unruptured intracranial aneurysms--risk of rupture and risks of surgical intervention. N Engl J Med. 1998; 339(24):1725-33.

4. Anxionnat R, Bracard S, Lebedinsky A, et al. [A survey of the management of unruptured intracranial aneurysms as practised by French neuroradiological and neurosurgical teams]. J Neuroradiol. 2008;35(2):90-8.
5. Finitsis S, Anxionnat R, Lebedinsky A, et al. Endovascular treatment of anterior communicating intracranial aneurysms. Report on a series of 280 patients. Interv Neuroradiol. 2010;16 (1):7-16.

6. Raymond J, Guilbert F, Weill A, et al. Long-term angiographic recurrences after selective endovascular treatment of aneurysms with detachable coils. Stroke. 2003;34(6):1398-403.

7. Roy D, Milot G, Raymond J. Endovascular treatment of unruptured aneurysms. Stroke. 2001;32(9):1998-2004.

8. Nieuwkamp DJ, Setz LE, Algra A, Linn FH, de Rooij NK, Rinkel GJ. Changes in case fatality of aneurysmal subarachnoid haemorrhage over time, according to age, sex, and region: a meta-analysis. Lancet Neurol. 2009;8(7):635-42.

9. Bederson JB, Connolly ES, Jr., Batjer HH, et al. Guidelines for the management of aneurysmal subarachnoid hemorrhage: a statement for healthcare professionals from a special writing group of the Stroke Council, American Heart Association. Stroke. 2009;40(3):994-1025.

10. van Gijn J, Rinkel GJ. Subarachnoid haemorrhage: diagnosis, causes and management. Brain. 2001;124(2):249-78.

11. Kowalski RG, Claassen J, Kreiter KT, et al. Initial misdiagnosis and outcome after subarachnoid hemorrhage. JAMA. 2004;291(7): 866-9.

12. Molyneux AJ, Kerr RS, Birks J, et al. Risk of recurrent subarachnoid haemorrhage, death, or dependence and standardised mortality ratios after clipping or coiling of an intracranial aneurysm in the International Subarachnoid Aneurysm Trial (ISAT): long-term follow-up. Lancet Neurol. 2009;8(5):427-33.

13. Broderick JP, Brown RD, Jr., Sauerbeck L, et al. Greater rupture risk for familial as compared to sporadic unruptured intracranial aneurysms. Stroke. 2009;40(6):1952-7.

14. Ishibashi $\mathrm{T}$, Murayama $\mathrm{Y}$, Urashima $\mathrm{M}$, et al. Unruptured intracranial aneurysms: incidence of rupture and risk factors. Stroke. 2009;40(1):313-16.

15. Juvela S, Porras M, Poussa K. Natural history of unruptured intracranial aneurysms: probability of and risk factors for aneurysm rupture. J Neurosurg. 2008;108(5):1052-60.

16. Satoh T, Omi M, Ohsako $\mathrm{C}$, et al. Influence of perianeurysmal environment on the deformation and bleb formation of the unruptured cerebral aneurysm: assessment with fusion imaging of 3D MR cisternography and 3D MR angiography. AJNR Am J Neuroradiol. 2005;26(8):2010-18.

17. van der Kolk NM, Algra A, Rinkel GJ. Risk of aneurysm rupture at intracranial arterial bifurcations. Cerebrovasc Dis. 2010;30(1): 29-35.

18. Wardlaw JM, White PM. The detection and management of unruptured intracranial aneurysms. Brain. 2000;123(2):205-21.

19. Weir B. Unruptured intracranial aneurysms: a review. J Neurosurg. 2002;96(1):3-42.

20. Wermer MJ, van der Schaaf I, Algra A, Rinkel GJ. Risk of rupture of unruptured intracranial aneurysms in relation to patient and aneurysm characteristics: an updated meta-analysis. Stroke. 2007;38(4): 1404-10.

21. Wiebers DO. Patients with small, asymptomatic, unruptured intracranial aneurysms and no history of subarachnoid hemorrhage should generally be treated conservatively: for. Stroke. 2005;36(2):408-9.

22. Matsumoto K, Akagi K, Abekura M, Nakajima Y, Yoshiminie T. Investigation of the surgically treated and untreated unruptured cerebral aneurysms of the anterior circulation. Surg Neurol. 2003;60(6):516-22.

23. Mira JM, Costa FA, Horta BL, Fabiao OM. Risk of rupture in unruptured anterior communicating artery aneurysms: metaanalysis of natural history studies. Surg Neurol. 2006;66(3): 12-19.

24. Raaymakers TW, Rinkel GJ, Limburg M, Algra A. Mortality and morbidity of surgery for unruptured intracranial aneurysms: a meta-analysis. Stroke. 1998;29(8):1531-8.

25. Yasunaga H, Matsuyama Y, Ohe K. Risk-adjusted analyses of the effects of hospital and surgeon volumes on postoperative complications and the modified Rankin scale after clipping of 
unruptured intracranial aneurysms in Japan. Neurol Med Chir (Tokyo). 2008;48(12):531-8.

26. King JT, Jr., Berlin JA, Flamm ES. Morbidity and mortality from elective surgery for asymptomatic, unruptured, intracranial aneurysms: a meta-analysis. J Neurosurg. 1994;81(6):837-42.

27. Gallas S, Drouineau J, Gabrillargues J, et al. Feasibility, procedural morbidity and mortality, and long-term follow-up of endovascular treatment of 321 unruptured aneurysms. AJNR Am J Neuroradiol. 2008;29(1):63-8.

28. Iijima A, Piotin M, Mounayer C, Spelle L, Weill A, Moret J. Endovascular treatment with coils of 149 middle cerebral artery berry aneurysms. Radiology. 2005;237(2):611-19.

29. Im SH, Han MH, Kwon OK, et al. Endovascular coil embolization of 435 small asymptomatic unruptured intracranial aneurysms: procedural morbidity and patient outcome. AJNR Am J Neuroradiol. 2009;30(1):79-84.

30. Pierot L, Spelle L, Vitry F. Immediate clinical outcome of patients harboring unruptured intracranial aneurysms treated by endovascular approach: results of the ATENA study. Stroke. 2008;39(9):2497-504

31. Standhardt H, Boecher-Schwarz H, Gruber A, Benesch T, Knosp E, Bavinzski G. Endovascular treatment of unruptured intracranial aneurysms with Guglielmi detachable coils: short- and long-term results of a single-centre series. Stroke. 2008;39(3): 899-904.
32. van Rooij WJ, Sluzewski M. Procedural morbidity and mortality of elective coil treatment of unruptured intracranial aneurysms. AJNR Am J Neuroradiol. 2006;27(8):1678-80.

33. Raftopoulos C, Goffette P, Vaz G, et al. Surgical clipping may lead to better results than coil embolization: results from a series of 101 consecutive unruptured intracranial aneurysms. Neurosurgery. 2003;52(6):1280-7.

34. Regli L, Dehdashti AR, Uske A, de Tribolet N. Endovascular coiling compared with surgical clipping for the treatment of unruptured middle cerebral artery aneurysms: an update. Acta Neurochir (Wien). 2002;82:41-6.

35. Darsaut TE, Findlay JM, Raymond J. The design of the Canadian UnRuptured Endovascular versus Surgery (CURES) trial. Can J Neurol Sci. 2011;38(2):236-41.

36. Solheim O, Eloqayli H, Muller TB, Unsgaard G. Quality of life after treatment for incidental, unruptured intracranial aneurysms. Acta Neurochir (Wien). 2006;148(8):821-30.

37. Yamashiro S, Nishi T, Koga K, et al. Improvement of quality of life in patients surgically treated for asymptomatic unruptured intracranial aneurysms. J Neurol Neurosurg Psychiatry. 2007;78 (5):497-500. 